\title{
CHAPTER 9 SETTLEMENT OF MACOMA BALTHICA LARVAE IN RESPONSE TO BENTHIC DIATOM FILMS
}

\author{
Accepted with minor revision as: \\ Van Colen C., Lenoir J., De Backer A., Vanelslander B., Vincx M., Degraer S., Ysebaert T. \\ Settlement of Macoma balthica larvae in response to benthic diatom films \\ Marine Biology
}

\section{Abstract}

We investigated the role of multi-species benthic diatom films (BDF) on the settlement of Macoma balthica larvae in mesocosm still-water experiments and flume experiments. Observations during five minutes revealed that in a stillwater environment, the larval settlement response was lower and the average burrowing time (i.e. penetration into the BDF) was slower in older BDF as compared to control and younger BDF. The different settlement responses to different ages of BDF were related to the concentration of chlorophyll $a$ and extracellular polymeric substances of the BDF, suggesting that a higher physical resistance during penetration into a dense matrix of diatoms and its associated sugar and protein compounds results in a lower settlement response in dense BDF at the very short term. In a hydrodynamic environment, M. balthica larvae settled significantly more in BDF as compared to control sediments. Comparison with the settlement of polystyrene mimics and freeze-killed larvae revealed that, active selection, active secondary dispersal and, at low flow velocities $\left(5 \mathrm{~cm} \mathrm{~s}^{-1}\right)$, also passive adhesion are important mechanisms that determine the settlement success of $M$. balthica larvae in estuarine biofilms. 
Our findings suggest that benthic diatoms may significantly affect $M$. balthica settlement behaviour and recruitment in estuarine tidal flats.

Keywords: Benthic diatom film, Larval settlement, Hydrodynamics, Settlement preferences, Macoma balthica

\section{Introduction}

One of the most important challenges in estuarine benthic ecology is to understand the spatial and temporal variability in soft-sediment communities. Recruitment is of fundamental importance to macrobenthic community structure because it is the foundation upon which all subsequent interactions within the community take place (Woodin et al. 1995).

The majority of marine macrobenthic invertebrates display a life cycle with a dispersive (i.e. pelagic) larval phase during which they distribute and settle down into new habitats and develop to the benthic stage. Settlement of marine benthic invertebrates is mediated by a wide set of factors, e.g. flow characteristics (Crimaldi et al. 2002), organic content of the sediment (Grassle et al. 1992), sediment disturbance (Woodin et al. 1998, Marinelli \& Woodin 2002, Marinelli \& Woodin 2004), sediment grain size (Pinedo et al. 2000), nutrient pore water concentrations (Engstrom \& Marinelli 2005), presence of conspecific juveniles or adults (Snelgrove et al. 2001), metabolites of sympatric organisms (Woodin et al. 1993, Esser et al. 2008) and the presence of bacteria (Dobretsjov \& Qian 2006, Sebesvari et al. 2006). Furthermore, during recent years, there is growing evidence that also marine biofilms are instrumental to habitat selection and the onset of settlement events for many benthic organisms (reviewed in Qian et al. 2007).

Marine biofilms are highly variable in time and composition, forming complex aggregates composed of diatoms, bacteria, protozoa and fungi (Decho 2000), all enmeshed in a matrix of extracellular polymeric substances (EPS). Both facilitative and inhibitive effects of marine biofilms on larval settlement have 
been reported, which are often attributed to waterborne bacterial EPS depending on origin, surface chemistry, micro-topography and metabolic activity of the biofilm (reviewed in Qian et al. 2007). The proportion of benthic diatoms in biofilms of estuarine tidal mudflats can be significantly high (Sabbe \& Vyverman 1991, MacIntyre et al. 1996). Lam et al. (2003) showed that relative space occupation of diatoms can mediate larval settlement of the polychaete Hydroides elegans. Hence, next to the bacterial compound of a marine biofilm, also the specific role of diatoms in the settlement of tidal flat invertebrate larvae requires specific interest. Moreover, postlarvae of herbivore benthic invertebrates often feed on diatoms. Thus, recruitment success of these larvae may depend on differences in diatom community composition because of their post-larval dietary requirements.

Marine biofilms have intensively been investigated with respect to their role in larval settlement of barnacles, ascidians, bryozoans, sea urchins, gastropods and polychaetes (e.g. Keough \& Raimondi 1995, Olivier et al. 2000, Harder et al. 2002, Lam et al 2003, 2005, Dahms et al. 2004, Sebesvari et al. 2006, Chiu et al. 2006, Dworjanyn \& Pirozzi 2008) but far less is known about diatom film mediation on bivalve settlement, especially in soft-sediments. The baltic tellin $M$. balthica is an infaunal surface deposit-feeding and facultative suspension feeding bivalve (Rossi et al. 2004) which displays a pelagic larval stage (Caddy 1967). This species occurs from the Gironde estuary in Southwest France to the polar region in Greenland and Siberia (Meehan 1985). In north-western European tidal flats, $M$. balthica is one of the most common bivalves that reaches densities ranging from tens to hundreds of individuals $\mathrm{m}^{-2}$ (Beukema 1976, Van Colen et al. 2006, 2008) and is an important food source for wading birds, benthic and epibenthic organisms (Hulscher 1982, Zwarts \& Blomert 1992, Hiddink et al. 2002a, b). Further, this species influences the geochemistry of the sediment, and thus tidal flat energy cycling in general, by their bio-engineering impact due to burrowing and feeding actions (e.g. Marinelli \& Williams 2003). Hence, successful recruitment of $M$. balthica, and bivalves in general, is of crucial importance to maintain tidal flat ecosystem functioning. 
In general, the final recruitment success is determined by two major classes of processes: (1) primary dispersal and initial settlement and (2) post-settlement processes (i.e. mortality and secondary dispersal and settlement) (Armonies 1992). In this paper, we report and discuss the results of larval response tests of the bivalve Macoma balthica to multi-species benthic diatom films (BDF), using still-water assays and flume experiments. Multiple choice flume experiments enable the determination of settlement preferences because bivalve larvae can select a preferred settlement site in a hydrodynamic environment (e.g. Grassle et al 1992, Snelgrove et al. 1998, Engstrom \& Marinelli, 2005). In addition, observations from still-water assays provide valuable information on some specific conditions which influence successful establishment within a given habitat (Marinelli \& Woodin 2004).

Specifically, the following null hypotheses concerning $M$. balthica larval settlement in response to BDF were tested:

Hor: Settlement response (i.e. rejection/acceptance) does not differ between different ages of BDF in a still-water environment (Experiment 1).

$H_{02}$ : Settlement choice is not influenced by BDF in a hydrodynamic environment (Experiment 2).

Ho2a: Settlement choice is not influenced by flow velocity.

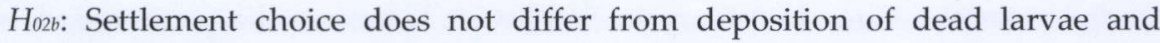
polystyrene mimics, thus settlement is a passive, depositional, process.

$H_{03}$ : In a hydrodynamic environment, the settlement response after primary settlement is not determined by BDF (Experiment 3). 


\section{Materials \& methods}

\section{Collection, production and cultivation of larvae}

\section{Collection}

Adult $M$. balthica were repeatedly collected from Paulinaschor (The Netherlands, $51^{\circ} 21^{\prime} 24^{\prime \prime} \mathrm{N}, 3^{\circ} 42^{\prime} 51^{\prime \prime}$ W) during low tide in February-March 2008 and stored at 5 ${ }^{\circ} \mathrm{C}$ in aerated basins $(40 \times 33 \times 14 \mathrm{~cm})$, prefilled with sieved sediment $(1 \mathrm{~mm})$ and 2 $\mu \mathrm{m}$ filtered seawater (FSW) with a salinity of $27 \pm 1$ practical salinity units (PSU).

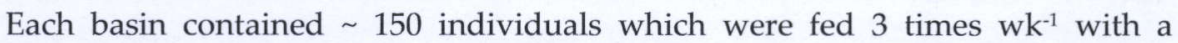
mixture of concentrated algae (Isochrysis galbana and Tetraselmis sp.; Reed Mariculture).

\section{Larval production}

Individual $M$. balthica were induced to spawn, following the procedure of Honkoop et al. (1999) and Bos (2005). Therefore, the adults were exposed to the selective serotonin re-uptake inhibitor (SSRI) fluoxetine, preceded by a $\Delta 10^{\circ} \mathrm{C}$ temperature shock. SSRI's prevent the deterioration of neurotransmitters, so nerves are stimulated longer and more intensely than usual (Honkoop et al. 1999). On average, $35 \%$ of the adults could be induced to spawn. Fertilisation was carried out by pipetting eggs of several females into a beaker and adding 1 to $3 \mathrm{ml}$ of sperm suspension derived from at least 5 males. The resultant mixture was left undisturbed for 4 hours at $15^{\circ} \mathrm{C}$. Fertilised eggs $(\varnothing \sim 100 \mu \mathrm{m})$ were then separated from all other matter by rinsing them over stacked sieves of 125 and 32 $\mu \mathrm{m}$. Subsequently, they were transferred into $2 \mathrm{~L}$ glass bottles (further referred to as batches), containing $15^{\circ} \mathrm{C}$ UV-irradiated filtered $27 \pm 1$ PSU seawater (UV FSW) dosed with $1.5 \times 10^{-5} \mathrm{~g}^{-1}$ Penicillin G potassium salt and $2.5 \times 10^{-5} \mathrm{~g}^{-1}$ streptomycin sulphate. The bottles were placed on a roller-table ( $3 \mathrm{rpm}$ ) to avoid sinking of larvae. 


\section{Cultivation \& maintenance}

At day 4, all larvae had reached the D-stage, named after its resemblance to the letter $\mathrm{D}$, and from this moment on, live Isochrysis galbana $\left(10^{5}\right.$ cells $\left.\mathrm{ml}^{-1}\right)$ was added to the UV FSW which was refreshed every other day. Subsamples were taken to measure larval mortality. During the cultivation, we observed a mortality of on average $36 \%$ of the brood stock at day 20 , which is a mortality rate of about $0.02 \mathrm{~d}^{-1}$. 21 to 24 days after fertilization, the larvae metamorphosed to the benthic stage as indicated by the development of a foot (i.e. pediveliger stage). 25 day old larvae $(270 \mu \mathrm{m} \pm 4$ SE $\mu \mathrm{m})$, actively moving their feet, were used in all experiments and are further referred to as M. balthica larvae or alive larvae (experiment 2).

\section{Settlement response in still-water (Experiment 1)}

\section{Sediment processing}

Sediment was collected from Paulinaschor at low tide. Collection was confined to the top $2 \mathrm{~cm}$ and sieved over a $1 \mathrm{~mm}$ mesh sized sieve in the laboratory to remove macrobenthic organisms and larger debris. Subsequently the sieved sediment was heated at $180^{\circ} \mathrm{C}$ during 4 hours. This sediment has a median grain size of $89.6 \pm 1.07 \mathrm{SE} \mu \mathrm{m}$ and the mud content is $30.8 \pm 0.52 \mathrm{SE} \%$ (Malvern Mastersizer 2000 laser diffraction) and is further referred to as control sediment. This sediment was preferred above muffled sediment as a control since pilot tests revealed an inhibitory impact of muffling on settlement responses which was not related to changes in organic content and or grain size. The inhibitory influence of muffled sediment therefore presumably relates to the dissolution of material from the muffled sediment into the water column.

For the assays, $2.5 \mathrm{~g}$ of control sediment was transferred into each well of a sterile 12-well microplate $\left(3.8 \mathrm{~cm}^{2}\right.$ well surface area, TPP, Switzerland) resulting in a 7 $\mathrm{mm}$ sediment layer. To develop a benthic diatom film (BDF), the control 
sediments were inoculated with $3 \mathrm{ml}$ of axenic diatom cultures and incubated at $18^{\circ} \mathrm{C}, 14 / 10$ hours day/night light regime $\left(145 \mu \mathrm{mol}\right.$ photons $\left.\mathrm{m}^{-2} \mathrm{~s}^{-1}\right)$. The diatoms used in this experiment were Navicula phyllepta, N. gregaria, N. arenaria and Cylindrotheca closterium. These species were isolated from the tidal mudflat at Paulinaschor and were dominant components of the microphytobenthos at that site (Sabbe \& Vyverman 1991, Forster et al. 2006). Cells for inoculations were harvested from monoclonal, exponentially growing cultures at $19^{\circ} \mathrm{C} \pm 1^{\circ} \mathrm{C}$ and illuminated at a rate of $90 \mu \mathrm{mol}$ photons $\mathrm{m}^{-2} \mathrm{~s}^{-1}$ with a light/dark cycle of 14/10 hours. The experimental microcosms were inoculated with a fixed total biovolume of $110^{8} \mu^{3}$ (biovolume of $N$. phyllepta, N. gregaria, N. arenaria $=310^{7}$ $\mu \mathrm{m}^{3}$; biovolume of $C$. closterium $=110^{7} \mu \mathrm{m}^{3}$ ). To obtain different BDF, sediments were incubated for $0,4,11$ and 21 days respectively for the control, "low", "medium" and "high" treatment. Every day, $1.2 \mathrm{ml}$ of the F/2 medium (Guillard 1975) of all treatments was refreshed in a flow bench without disturbing the sediment. Control sediments were maintained under the same incubation conditions. This resulted in an averaged C. closterium $-N$. phyllepta $-N$. arenariaN. gregaria relative biovolume of $14 \%-26 \%-32 \%-31 \%, 22 \%-17 \%-34 \%-26 \%$ and $27 \%-16 \%-31 \%-25 \%$, for the "low", "medium" and "high" treatment, respectively. Experimental sediments were further characterized by their Chla and EPS concentration. Chla concentration was determined by HPLC analysis of the supernatant, extracted from the lyophilized sediment by adding $10 \mathrm{ml} 90 \%$ acetone. The EPS concentration was measured spectrophotometrically using the phenol-sulphuric acid assay (Dubois et al. 1956) on the colloidal carbohydrate fraction of the supernatant extracted after lyophilization (De Brouwer \& Stal 2001).

\section{Experimental protocol}

In order to observe settlement responses (i.e. acceptance/rejection) to different ages of BDF, M. balthica larvae were labelled with fluorescent microparticles (Radglo, Radiant Color, N.V., Houthalen, Belgium) to obtain a contrast with the bioassay sediment. These microparticles are non-toxic and have a spherical 
diameter of 2 to $10 \mu \mathrm{m}$. Feeding larvae ingest these particles resulting in a gut region filled with fluorescent pigment (Lindegarth \& Jonsson 1991, Jonsson et al. 1991), which become visible by illumination of the larvae with UV-light ( $365 \mathrm{~nm}$ ). To assure uptake by the larvae, fluorescent pigment particles were supplied to feeding larvae $\left(10^{5}\right.$ particles $\left.\mathrm{ml}^{-1}\right) 24$ hours prior to the experiments. Since the particles are insoluble in water, one droplet of detergent was added to facilitate suspension of these particles. Preliminary test showed that mortality rate was not affected as a result of fluorescent labelling. Prior to the still-water bioassays, $2 \mathrm{ml}$ F/2 medium of each well was pipetted out and $2 \mathrm{ml}$ of 27 PSU sterile UV FSW was added to the wells without disturbing the sediment. Macoma balthica larvae were picked out from two independent batches, using a stereomicroscope and UV-light to check their viability and dyeing. For each bioassay ( $\left.\mathrm{n}=6 \mathrm{batch}^{-1}\right)$, fifteen larvae were gently added to a well with a glass pipette and timing started when the pipette was empty. All pipettes were checked for remaining larvae, i.e. larvae that were not added to the well. During 5 minutes the burrowing larvae were counted and their disappearance in the sediment was timed. After this time period, larvae that were still on the sediment surface were interpreted as not settled.

To quantify bacterial contamination of the BDF due to experimental handling procedures, bacteria were extracted from the biofilm, stained with Acridine Orange and bacterial cell densities were enumerated on $0.2 \mu \mathrm{m}$ black polycarbonate filters under blue-green light excitation (480 - $195 \mathrm{~nm})$. Recorded bacterial densities were marginal, varying between $160-630$ cells $\mathrm{mm}^{-2}$ and did not differ significantly between treatments ( $t$-test; $p>0.05$ ).

\section{Statistical analysis}

Burrowing time and percentage of larval settlement $\left(\mathrm{n}^{\circ}\right.$ of settled larvae $/ \mathrm{n}^{\circ}$ of total added larvae) after 60, 120, 180, 240 and 300 seconds were used as response variables to identify settlement responses of $M$. balthica larvae to the different biofilms. Burrowing time data were root transformed and percentage of larval settlement data were arcsine transformed to gain normality (Shapiro-Wilks' tests) 
and homogeneity of variances (Cochran \& Bartlett tests). The effect on burrowing time was investigated using two-factor analysis of variance with Batch as random factor and Treatment as fixed factor, followed by Tukey's multiple comparison post-hoc tests. Larval settlement data were analyzed using a repeated measures design with Batch as random factor and Treatment and Time as fixed factors. Tukey's multiple comparison tests were performed to investigate significant differences between treatments, whenever the Treatment within Batch factor was significant. Since the sphericity assumption for repeated measurements was violated by our data, adjusted F tests using the GreenhouseGeiser correction were calculated, resulting in more conservative p-levels (Quinn and Keough 2002). Further, regression analysis was performed to investigate relationships between the percentage of larval settlement, averaged burrowing time and the BDF characteristics (Chl $a$ and EPS).

\section{Annular flume experiments (Experiment 2 \& 3)}

\section{Annular flume characteristics}

According to the Plymouth Marine Laboratory annular flume (Widdows et al. 1998), a flume was constructed of polystyrene material, forming a circular channel $10 \mathrm{~cm}$ wide (inner $\varnothing 44 \mathrm{~cm}$, outer $\varnothing 64 \mathrm{~cm}$ ), $35 \mathrm{~cm}$ deep and with a maximum volume of $60 \mathrm{~L}$. The channel flow was driven by contact on the water surface with 4 pvc paddles $(9 \times 14 \mathrm{~cm})$, which were attached to a rigid support system driven by a variable speed DC motor. On the bottom of the tank, pvc pots (inner $\varnothing 5 \mathrm{~cm}$ ) can be attached, flush with the flume bottom and O-rings sealed the pots to prevent water loss. The annular flume is a good compromise in terms of portability and the spatial coverage $\left(0.17 \mathrm{~m}^{2}\right)$ and allowed simultaneous testing of treatments in a realistic fully developed benthic boundary layer where larvae and sediment treatments could easily be removed and recovered after each trial. The disadvantage of annular flumes in general is the effect of secondary circulation. However, secondary flows are kept to an acceptable 
minimum ( 3\% of tangential flow) with the $10 \mathrm{~cm}$ channel width of the flume in the current study (J. Widdows, pers. comments). To characterize the fluid dynamic environment, velocity profiles were measured at $8 \mathrm{~cm}$ above the bottom with a SonTek Micro ADV (Acoustic Doppler Velocimeter), mounted through the bottom of the flume. A linear relation between free stream velocity and rounds per minute was found (free stream velocity $=1.7785 \times R P M-0.5672\left(r^{2}=\right.$ 0.998)).

\section{Sediment processing}

The same control sediment as for the still-water bioassays was used. To yield the BDFs, the pvc-pots, prefilled with control sediment, were inoculated with a mixture of diatoms (total biovolume $=4.6810^{8} \mu \mathrm{m}^{3}$; relative biovolume $=30-30$ $30-10 \%$, respectively for $N$. phyllepta, N. gregaria, N. arenaria and C. closterium). Control and BDF sediments were incubated for 11 days at $18^{\circ} \mathrm{C}, 14 / 10$ hours day/night light regime (145 $\mu \mathrm{mol}$ photons $\left.\mathrm{m}^{-2} \mathrm{~s}^{-1}\right)$ and $10 \mathrm{ml}$ of the $\mathrm{F} / 2$ medium was refreshed every day. Chla and EPS concentrations of the upper $5 \mathrm{~mm}$ were determined according to the abovementioned methods (Experiment 1).

\section{Settlement choice in a hydrodynamic environment (Experiment 2): protocol}

The proportional distribution of alive larvae, freeze-killed larvae (further referred to as dead Macoma) and spherical polystyrene (PS) mimics (ø 250-400 $\mu \mathrm{m})$ between BDF and control sediments was tested in a first set of experiments to examine processes affecting settlement of $M$. balthica larvae (i.e. active habitat selection vs. passive deposition). Therefore two BDF and two control sediments were screwed into the bottom of the flume (flume bottom surface occupied $=4.6$ $\%$; intersect between pots $=37.4 \mathrm{~cm})$ for each experimental trial $(\mathrm{n}=4)$ and the flume was filled with $50 \mathrm{~L}$ of FSW ( $\left.15^{\circ} \mathrm{C}, 27 \mathrm{PSU}\right)$. Subsequently, 500 juvenile Macoma and $~ 5000$ PS mimics were randomly added to the flume and flow was initiated and maintained for 3 hours at $5 \mathrm{~cm} \mathrm{~s}^{-1}$ or $15 \mathrm{~cm} \mathrm{~s}^{-1}$. In addition, two 
trials at $5 \mathrm{~cm} . \mathrm{s}^{-1}$ and two trials at $15 \mathrm{~cm} \mathrm{~s}^{-1}$ were conducted with 500 dead larvae. Sinking velocities of the three types of 'settlers' in $15^{\circ} \mathrm{C}, 27$ PSU still FSW were $2.8 \pm 0.5 \mathrm{SE} \mathrm{mm} \mathrm{s}{ }^{-1}, 2.6 \pm 0.2 \mathrm{SE} \mathrm{m^{-1 }}$ and $1.6 \pm 0.2 \mathrm{~mm} \mathrm{~s}^{-1}$, respectively for alive larvae, dead larvae and PS mimics. Furthermore, no resuspension of the sediment was observed at $5 \mathrm{~cm} \mathrm{~s}^{-1}$ and $15 \mathrm{~cm} \mathrm{~s}^{-1}$ during pilot tests performed with neutral red dyed sediment. Hence, secondary dispersal after primary settlement is expected due to active choice, rather than occurring passively by sediment resuspension. After 3 hours, the experimental sediments were closed with inox plates, the flume was drained and the top $2 \mathrm{~cm}$ of the sediments was preserved in a $4 \%$ buffered formalin - tap water solution, stained with Rose Bengal and the settled juveniles were sorted out under a stereomicroscope.

Settlement response after primary settlement (Experiment 3): protocol

Thirty M. balthica larvae were added to the control and BDF sediments and left to settle for 30 minutes. Subsequently the above standing F/2 medium was removed from each pvc pot and checked for unsettled juveniles. For each experimental trial, two control and two BDF sediments were screwed into the flume, flush with the flume bottom. Then, the flume was filled with $50 \mathrm{~L}$ of FSW $\left(15^{\circ} \mathrm{C}, 27\right.$ PSU) and the flow was initiated at $5 \mathrm{~cm} \mathrm{~s}^{-1}$. After 10 minutes, the flow was stopped and the experimental sediments were closed with inox plates, the flume was drained and the top $2 \mathrm{~cm}$ of the sediments was preserved in a $4 \%$ buffered formalin - tap water solution, stained with Rose Bengal and the settled juveniles were sorted out under a stereomicroscope.

\section{Statistical analysis}

For Experiment 2, replicated G-tests for goodness of fit (Sokal \& Rohlf 1995) were conducted to determine significant deviations from the $1 / 1$ (i.e. even) distribution, the averaged distribution of the PS mimics, dead larvae and the averaged distribution of alive larvae, dead larvae and PS mimics at $15 \mathrm{~cm} \mathrm{~s}^{-1}$. The two BDF and the two control sediments per experimental trial were pooled and 
only the juvenile \% inside sampling pots was retained for statistical analysis. All results have been expressed as relative \% recovered from BDF and control sediments and the percentages were adjusted to give composition, i.e. their cumulative abundance equals $100 \%$. As such, the weight of all replicates in a replicated statistical test is equal (Moens et al. 1999). Measurement of the pooled $\mathrm{G}$ statistic $\left(\mathrm{G}_{\mathrm{p}}\right)$ enabled interpretation of the significance of the overall deviation from the tested distribution over all replicates. $G_{p}$ was calculated at a critical probability of $\alpha^{\prime}=\alpha / \mathrm{k}$, with $\mathrm{k}$ equal to the number of multiple pairwise tests (i.e. Bonferroni approach). As such, G-tests for PS mimics and alive larvae were performed at $\alpha=0.008$ (i.e. 0.05/6). Experiment 3 was analyzed using a mixed model analysis of variance with Batch and Trial as random effects and Treatment as fixed effect. The proportion remaining to the sediments was arcsine-square root transformed to meet assumptions of normality (Shapiro-Wilks' tests) and homogeneity of variances (Cochran \& Bartlett tests).

\section{Results}

\section{Benthic Diatom Film characteristics}

Manipulation of the incubation time successfully resulted in different BDFs. Chlorophyl $a$ and EPS concentration of these BDFs (Table 1) were significantly different between treatments for each experiment (t-test, $\mathrm{p}<0.05$ ). Initiation of the flow slightly reduced the Chla content of the BDF $(-14 \%,-12 \%$ and $-29 \%$; respectively for $10 \mathrm{~min}$ at $5 \mathrm{~cm} \mathrm{~s}^{-1}, 3$ hours at $5 \mathrm{~cm} \mathrm{~s}^{-1}$ and 3 hours at $15 \mathrm{~cm} \mathrm{~s}^{-1}$ ) due to biofilm erosion during the first minute after initiation of the flow. However, differences between control and BDF sediments remained large and significant (t-test, $\mathrm{p}<0.05)$. 


\begin{tabular}{lcc}
\hline & $\begin{array}{c}\text { Chla } \\
\left(\mu \mathrm{g} \cdot \mathbf{g}^{-1} \text { dry sediment) }\right.\end{array}$ & $\begin{array}{c}\text { EPS } \\
\text { (g glucose. } \mathbf{g}^{-1} \text { dry sediment) }\end{array}$ \\
\hline Control sediment & $0.01 \pm 2.010^{-4}$ & $1.110^{-4} \pm 7.910^{-6}$ \\
Experiment 1 & & \\
4 day old & $3.13 \pm 0.81$ & $1.610^{-4} \pm 5.510^{-5}$ \\
11 day old & $8.46 \pm 0.59$ & $1.810^{-4} \pm 5.910^{-5}$ \\
21 day old & $15.35 \pm 3.6$ & $2.310^{-4} \pm 7.810^{-5}$ \\
Experiment 2 \& 3 & & $1.710^{-4} \pm 2.910^{-7}$ \\
11 day old & $7.04 \pm 1.17$ & \\
\hline
\end{tabular}

Table 1. Chla and EPS concentration $\pm S E$ of the benthic diatom film and control sediments in all experiments. Determination of BDF characteristics is based on the upper $7 \mathrm{~mm}$ of the sediment for Experiment 1 and the upper $5 \mathrm{~mm}$ of the sediment for Experiment 2 and 3.

\section{Settlement response in still-water (Experiment 1)}

All Macoma larvae started to burrow within the first minute after their addition to the wells. The percentage of larval settlement significantly differed between treatments and times. Consequently, $H_{01}$ was rejected, i.e. the settlement response differed between different ages of BDF in a still-water environment. No significant differences between the two batches were found and the interaction between Time and Treatment nested in Batch was not significant (Table 2). In general, the settlement response to controls and 4 day old BDF was higher than in 11 day old and 21 day old BDF. The percentage of larval settlement increased with time for all treatments and, in Batch 1, significant differences remained between 11 day old BDF and control sediments, even after 300 seconds (Tukey's test, $\mathrm{p}<0.05$ ) (Fig 1a). Consistently, the average burrowing time was significantly different between treatments with highest burrowing times in 11 day old and 21 day old BDF for both batches (Table 3, Fig1b). The percentage of larval settlement was significantly negatively related to the Chla concentration and the 
colloidal EPS fraction of the BDFs $\left(\mathrm{r}^{2}=0.68\right.$ and $\mathrm{r}^{2}=0.52$; respectively). No significant relations were found between the averaged burrowing time per treatment and BDF characteristics.

\section{Settlement choice (Experiment 2)}

Mean recovery rate of alive and dead larvae was $98 \%$ at both flow velocities, indicating that loss of larvae due to stickiness to the walls and paddles is marginal. On average, $5.8 \pm 1.5 \mathrm{SE} \%$ of the live larvae and $6.0 \pm 1.5 \mathrm{SE} \%$ of the dead larvae were recovered in the control and BDF sediments at $5 \mathrm{~cm} \mathrm{~s}^{-1}$. At 15 $\mathrm{cm} \mathrm{s}^{-1}$, the total percentages of settlement in control and BDF sediments were 4.6 $\pm 1.5 \mathrm{SE} \%$ and $4.4 \pm 1.4 \mathrm{SE} \%$, respectively for alive larvae and dead larvae. Significantly more live larvae settled in BDF than in control sediments at $5 \mathrm{~cm} \mathrm{~s}^{-1}$ $(\mathrm{G} p=36.6, \mathrm{p}<0.001)$ and $15 \mathrm{~cm} \mathrm{~s}^{-1}(\mathrm{Gp}=59.2, \mathrm{p}<0.001)$ and the distribution of alive larvae did not differ between both flow velocities $(\mathrm{Gp}=2.9, \mathrm{p}=0.087)$. Consequently, $\mathrm{H}_{02}$ is rejected while $\mathrm{H}_{02 a}$ cannot be rejected, i.e. settlement is influenced by BDF but the settlement preference for BDF is independent of flow velocity.

The distribution of PS mimics did not differ significantly from the even distribution at both flow velocities $(\mathrm{Gp}=6.8, \mathrm{p}=0.009 ; \mathrm{Gp}=0.3, \mathrm{p}=0.56$, respectively for $5 \mathrm{~cm} \mathrm{~s}^{-1}$ and $15 \mathrm{~cm} \mathrm{~s}^{-1}$ ). Consistently, the distribution of alive larvae significantly differed from the passive deposition of PS mimics at both flow velocities $\left(\mathrm{Gp}=71.3, \mathrm{p}<0.001 ; \mathrm{Gp}=72.0, \mathrm{p}<0.001\right.$, respectively for $5 \mathrm{~cm} \mathrm{~s}^{-1}$ and $\left.15 \mathrm{~cm} \mathrm{~s}^{-1}\right)$. Hence, $H_{02 b}$ is rejected, i.e. habitat selection for BDF is not a passive, depositional process. However, deposition of dead larvae was significantly higher in BDF at $5 \mathrm{~cm} \mathrm{~s}^{-1}(66 \%$; $\mathrm{Gp}=20.8, \mathrm{p}<0.001)$, whereas the distribution of dead larvae did not differ significantly from the even distribution at $15 \mathrm{~cm} \mathrm{~s}^{-1}(\mathrm{Gp}=1.0, \mathrm{p}=0.32)$. Hence, based on comparison between distribution of dead and alive larvae, $H_{02 b}$ could only be rejected at a flow velocity of $15 \mathrm{~cm} \mathrm{~s}^{-1}$. 

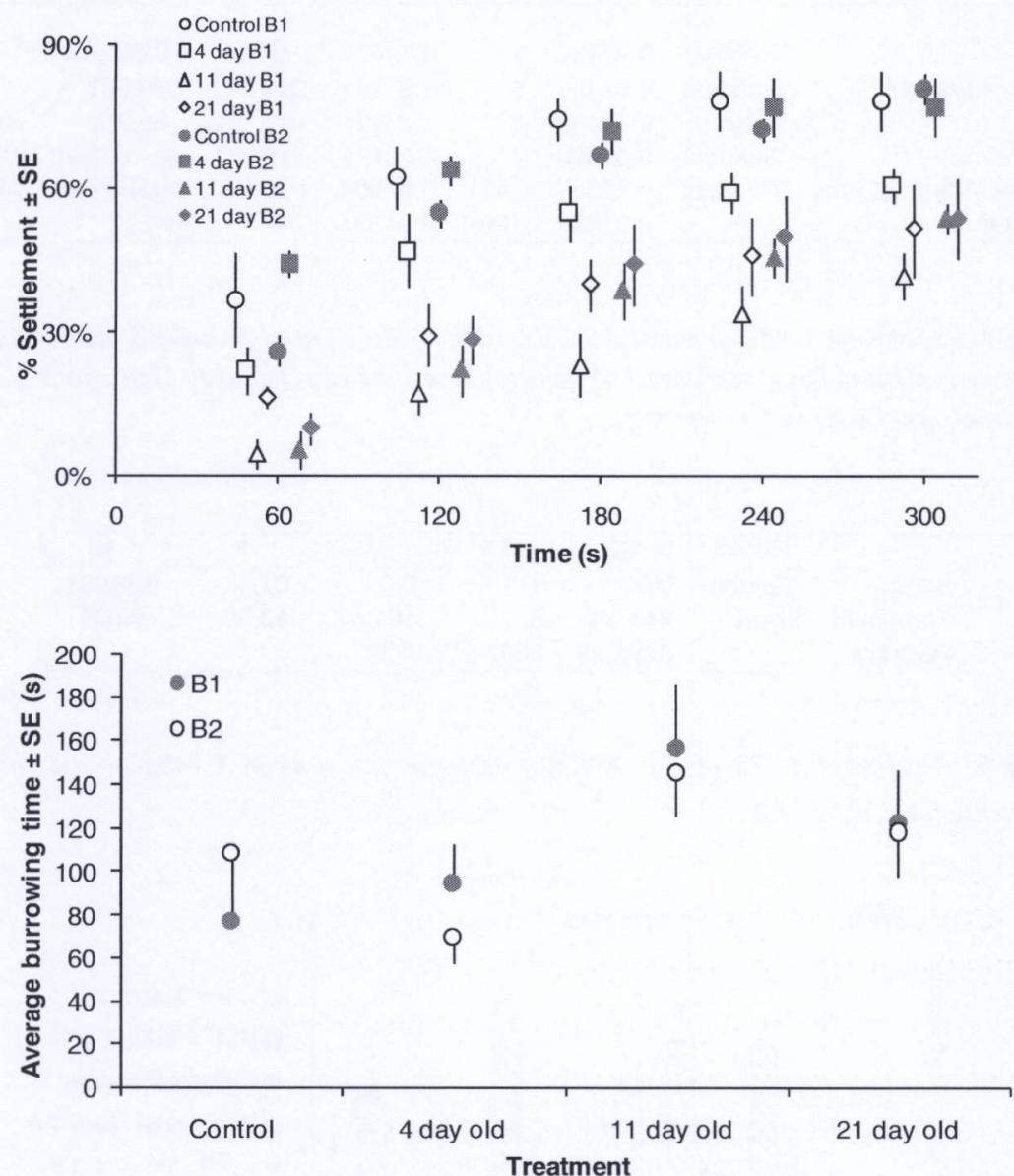

Fig. 1. Experiment 1. Upper panel: the percentage of settlement in the different treatments in relation with the time after addition of the larvae. Data plotted are means of six replicates per batch. Lower case letters indicate significant differences between treatments at each Time. Lower panel: averaged burrowing time $\pm S E$ of the larvae in the different treatments. $B 1=$ batch $1, B 2=$ batch 2. Lower case letters indicate significant differences between treatments. 


\begin{tabular}{llllllll}
\hline & Effect & SS & Df & MS & F & p & $\begin{array}{c}\text { G-G } \\
\text { adjusted } \\
\text { p }\end{array}$ \\
\hline Batch & Random & 0.13432 & 1 & 0.13432 & 0.2012 & 0.669487 & \\
Treatment(batch) & Random & 4.02861 & 6 & 0.67144 & 96.7442 & $<0.001$ & \\
Time & Fixed & 4.01163 & 4 & 1.00291 & 138.3899 & $<0.001$ & $<0.001$ \\
Batch*Time & Random & 0.02899 & 4 & 0.00725 & 1.0377 & 0.407856 & 0.99304 \\
Treatment(Batch)*Time & Random & 0.16657 & 24 & 0.00694 & 0.4967 & 0.977122 & 0.91774 \\
Residual & & 2.51526 & 180 & 0.01397 & & & \\
\hline
\end{tabular}

Table 2. Experiment 1. Mixed model ANOVA table for the effect of Treatment, Batch and Time on the percentage of larval settlement. Adjusted p-levels are calculated for Time effects based on the Greenhouse-Geiser (GG) correction.

\begin{tabular}{lllllcl}
\hline & Effect & \multicolumn{1}{c}{ SS } & Df & \multicolumn{1}{c}{ MS } & \multicolumn{1}{c}{$\mathbf{F}$} & \multicolumn{1}{c}{ P } \\
\hline Batch & Random & 0.33 & 1 & 0.33 & 0.04 & 0.850811 \\
Treatment & Fixed & 544.40 & 3 & 181.47 & 19.35 & $<\mathbf{0 . 0 0 1}$ \\
Residual & & 3282.39 & 350 & 9.38 & & \\
\hline
\end{tabular}

Table 3. Experiment 1. Two-factor ANOVA table for the effect of Treatment and Batch on burrowing time.

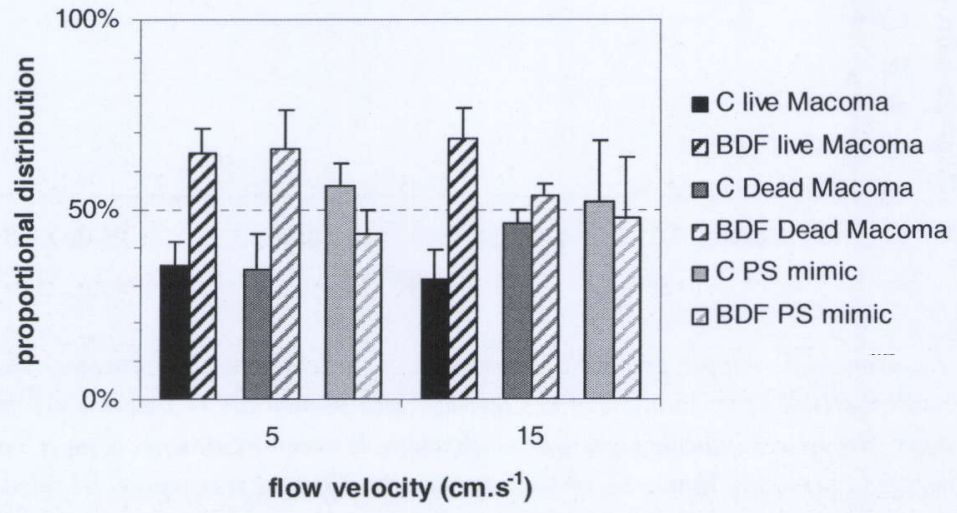

Fig. 2. Experiment 2. Proportional distribution $\pm S E$ of the recruited alive Macoma, dead Macoma and PS mimics and dead pediveliger mimics in control (c) and benthic diatom film (bdf) sediments at $5 \mathrm{~cm} \mathrm{~s}^{-1}$ and $15 \mathrm{~cm} \mathrm{~s}^{-1}$. 


\section{Settlement response after primary settlement (Experiment 3)}

Analysis of the above standing medium showed a larval addition efficiency of $100 \%$ in both control and BDF sediments. Retention rates of M. balthica larvae were significantly higher in BDF (58 \%) as compared to controls (40\%)(Fig. 3, Table 4). Despite the lower larval retention rate to BDF in Trial B of Batch 2, no Batch nor a Trial effect was found indicating that, overall, the strength of response did not significantly vary over replicates. Consequently, $\mathrm{H}_{03}$ was rejected, i.e. secondary dispersal after primary settlement is influenced by BDF.

\begin{tabular}{lcccccc}
\hline & Effect & SS & Df & MS & F & p \\
\hline Treatment & Fixed & 0.034331 & 1 & 0.034331 & 10.799 & $\mathbf{0 . 0 2 1 8 0 5}$ \\
Batch & Random & 0.002726 & 1 & 0.002726 & 2.066 & 0.224013 \\
Trial (Batch) & Random & 0.005279 & 4 & 0.001320 & 0.415 & 0.792597 \\
Residual & & 0.015895 & 5 & 0.003179 & & \\
\hline
\end{tabular}

Table 4. Experiment 3. Mixed model ANOVA table for the effect of Treatment and Trial on the percentage of remaining larvae.

\section{Discussion \& conclusions}

In this study we investigated the role of multi-species benthic diatom films on the settlement of Macoma balthica larvae. Successful settlement is a crucial element in the recruitment of invertebrate larvae and thus in determining macrobenthic community structure. Settlement of invertebrate larvae is known to be mediated by marine biofilms and both biofilm induced facilitative and inhibitive effects on settlement have been demonstrated (reviewed in Pawlik 1992, Wieczorek et al. 1995). Our results show that the settlement of M. balthica larvae is also influenced by benthic diatoms and the outcome of the different experiments allows the suggestion of the underlying mechanisms. 


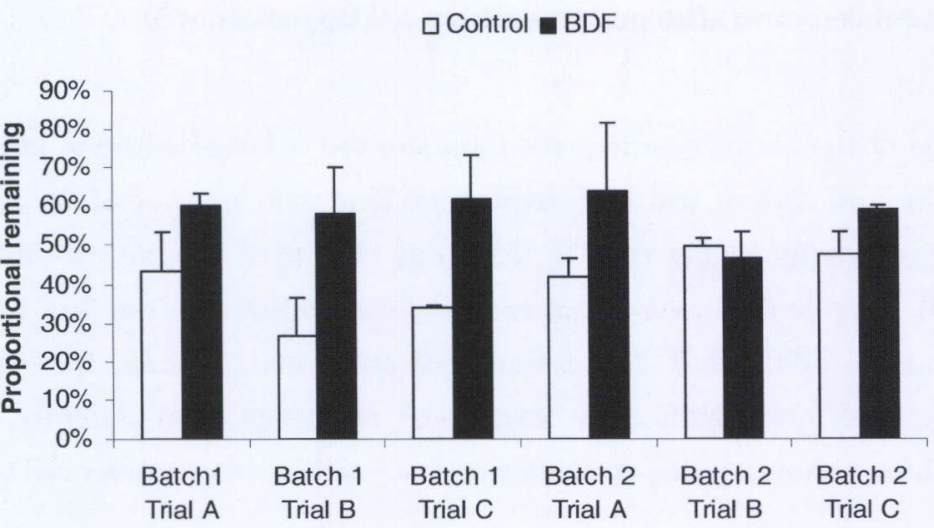

Fig. 3. Experiment 3. Retention percentages $\pm S E$ of primary settled larvae in response to BDF (black bars) and control sediments (white bars).

In a still-water environment, the average burrowing time depends on the age of BDF. During the first five minutes after inoculation, the settlement response was higher and the average burrowing time was faster in controls and younger BDF than in older BDF. Although the role of diatom-derived chemical cues cannot be ruled out, our results suggest that a physically mediated process is probably responsible for this difference in settlement response. First, in all treatments, larvae started to burrow directly after their inoculation and no "rejection behavior" was observed. Second, no significant differences were found between controls and 4 day old BDF, neither for \% of settlement, nor for burrowing time. Third, complete settlement in dense BDF sediments was observed in still water after 30 minutes, preceding addition to the flume in Experiment 3. A higher resistance during penetration into a dense matrix of diatoms and their associated sugar and protein compounds therefore probably resulted in a reduced settlement in old, dense BDF at the short-term. This hypothesis is supported by the negative relationship between the \% of larval settlement and the Chl $a$ and colloidal EPS concentration. At the very short-term, settling $M$. balthica larvae in dense BDF are therefore, more susceptible to epibenthic predation in comparison with larvae that burrow in less dense BDF. However, at the medium and longer 
term, a beneficial effect may be expected in dense BDF due to better growing conditions as a result of the high food supply, making the bivalves also less susceptible to epibenthic predation (Hiddink et al. 2002, Hiddink 2003).

Macoma balthica larvae settled significantly more in BDF as compared to the controls and this distribution was not significantly different between flow velocities of $5 \mathrm{~cm} \mathrm{~s}^{-1}$ and $15 \mathrm{~cm} \mathrm{~s}^{-1}$. However, the underlying mechanism of habitat selection seems to differ between both flow velocities. At $15 \mathrm{~cm} \mathrm{~s}^{-1}$, significantly higher proportions of $M$. balthica larvae settled in BDF as compared to PS mimics and dead larvae, which both displayed a not significantly different recruitment pattern from the even distribution (i.e. no preference). At $5 \mathrm{~cm} \mathrm{~s}^{-1}$, however, dead larvae performed a similar preference for BDF as alive $M$. balthica larvae, suggesting passive deposition of larvae to the BDF as a settlement mechanism at this flow velocity. The difference between inert, spherical PS mimics and dead, flatter larvae suggests that flow-dependent adhesion to the biofilm is an important settlement mechanism at lower flow velocities. Adhesion to biofilms is a complex process which remains poorly understood, but biochemical (e.g. production of viscoelastic substances, wettability of the surface), behavioral or physical (e.g. surface energy of the substratum) mechanisms may all be involved (Zardus et al. 2008). At higher flow velocities, substratum shear stress may be too high, inhibiting passive adhesion of dead larvae to the biofilm and the enhanced settlement of M. balthica larvae in BDF is due to active selection. Furthermore, the results obtained from experiment 3 highlight the importance of post-settlement dispersal in the final habitat selection. Thus, next to passive adhesion to the biofilm, also active behavior (i.e. rejection of the initial settlement site) plays a role at low flow velocities. Whenever no suitable settlement site is encountered, M. balthica larvae can actively re-enter the water column after initial settlement by migration to the surface and secreting a byssus thread, which allows resuspension along with currents (i.e. byssus drifting, Beukema \& de Vlas 1989).

Higher recruitment success into dense biofilms has been noticed in the field for Macoma balthica (Van Colen et al. 2008) and for benthic invertebrates in general (e.g. Keough \& Raimundi 1995). Furthermore, within the whole distribution area 
of $M$. balthica, primary settlement of postlarvae occurs predominantly on high tidal flats and offshore secondary dispersal occurs from late summer on towards the lower tidal flats (Reading 1979, Martini \& Morrison 1987, Beukema \& de Vlas 1989, Van der Meer et al. 2003). Beukema \& de Vlas (1989) and Hiddink (2003) attribute this preference for primary settlement at high tidal flats to the lower predation pressure of epifaunal organisms and the lower disturbance by wave action at these sites. Furthermore, as a result of lower sediment resuspension, biofilms tend to develop more stable and are more productive in the more sheltered, upshore tidal flats (de Jong \& de Jonge 1995). Hence, taken our results into account, enhanced primary settlement of $M$. balthica pediveligers in the upper tidal flats may, next to the above mentioned theories, also result from habitat selection for biofilms. However, the nature of the diatom-derived settlement cue for $M$. balthica larvae remains unknown. Such settlement cues have extensively been studied in relation to the bacterial compound of the biofilm (e.g. Bao et al. 2007), whereas the specific cues derived from diatoms have been investigated to a much lesser extent. Based on manipulation of the different components of biofilms, Lam et al. (2003) reported that the settlement of the serpulid polychaete Hydroides elegans is induced due to the presence of capsular surface EPS, produced by specific diatoms. Such diatom-derived sugar compounds have also been identified as settlement and metamorphosis cues for barnacles, limpets and bryozoans (Dahms et al. 2004, Patil \& Anil 2005, Jouuchi et al. 2007). Further experiments, in which the chemical compounds derived from the different diatom species (e.g. EPS) are manipulated, are needed to elucidate these diatom-derived cues regarding the settlement of $M$. balthica larvae.

\section{Acknowledgments}

This research is supported by the Institute for the Promotion of Innovation through Science and Technology in Flanders, Belgium (IWT Vlaanderen). We would like to thank John Widdows and Peter Herman for their comments on the flume and experimental design, Tjeerd Bouma for his help with the ADV measurements, Jurgen Verstraeten and Yves Israël for the construction of the 
annular flume and Annick Verween, Annick Van Kenhove, Danielle Schram, Annelien Rigaux and Dirk Van Gansbeke for their assistance during processing of the samples and maintenance of the larval cultivation. This paper contributes to the Ghent University BBSea Project (GOA 01600705) and the EU Network of Excellence Marbef (GOCE-CT-2003-505446). 